\title{
Effects of Mixing Ratio of Silicon Carbide Particles on the Etch Characteristics of Reaction-Bonded Silicon Carbide
}

\author{
Youn-Woong Jung, Hangjoon Im, Young-Ju Kim*, Young-Sik Park*, \\ Jun-Baek Song*, and Ju-Ho Lee* \\ Department of Advanced Materials Engineering, Korea Polytechnic University, Siheung 15073, Korea \\ *R\&D center, DSTechno Co., Ltd., Wonju 26498, Korea
}

(Received January 12, 2016; Revised March 4, March 31, 2016; Accepted April 1, 2016)

\begin{abstract}
We prepared a number of reaction-bonded silicon carbides (RBSCs) made from various mixing ratios of raw $\mathrm{SiC}$ particles, and investigated their microstructure and etch characteristics by Reactive Ion Etch (RIE). Increasing the amount of $9.5 \mu \mathrm{m}$-SiC particles results in a microstructure with relatively coarser Si regions. On the other hand, increasing that of $2.6 \mu \mathrm{m}$-SiC particles produces much finer Si regions. The addition of more than $50 \mathrm{wt} \%$ of $2.6 \mu \mathrm{m}$-SiC particles, however, causes the microstructure to become partially coarse. We also evaluated their etching behaviors in terms of surface roughness (Ra), density and weight changes, and microstructure development by employing Confocal Laser Scanning Microscope (CLSM) and Scanning Electron Microscope (SEM) techniques. During the etching process of the prepared samples, we confirmed that the residual Si region was rapidly removed and formed pits isolating $\mathrm{SiC}$ particles as islands. This leads to more intensified ion field on the $\mathrm{SiC}$ islands, and causes physical corrosion on them. Increased addition of $2.6 \mu \mathrm{m}$-SiC particles produces finer residual $\mathrm{Si}$ region, and thus decreases the surface roughness (Ra.) as well as causing weight loss after etching process by following the above etching mechanism.
\end{abstract}

Key words : Reaction-bonded silicon carbide, Reactive ion etch, Residual silicon, Etch mechanism

\section{Introduction}

$\mathbf{R}$ ecently, line width of semiconductors has reduced to $10 \mathrm{~nm}$, and microprocessing techniques are becoming more and more sophisticated. The top-down process for pattern forming technology includes Double Patterning Technology (DPT), Quadruple Patterning Technology (QPT), and Extreme Ultraviolet (EUV) technology. In actual practice, however, Self-aligned DPT (SaDPT) and Self-aligned QPT (SaQPT) are most preferred by using repeated sequences of Chemical Vapor Deposition (CVD), etch, and Chemical Mechanical Planarization (CMP). Compared to conventional processes, these newly-emerged technologies employ a CVD process instead of photolithograph for the formation of a sacrificial layer. Thus, they require a considerable number of etching and CMP processes for a fine pattern formation.

Especially, the etch process consists of DPT or QPT sequences, which are equivalent to three and five SPT (single patterning technology) processes, respectively. This leads to much longer exposure of various chamber components to the high powered and reactive plasma source. ${ }^{1)}$ For the etch processes by DPT and QPT, therefore, the use of reaction-bonded silicon carbide (RBSC) has increased

${ }^{\dagger}$ Corresponding author : Hangjoon Im

E-mail : hjim@kpu.ac.kr

Tel : +82-31-8041-0582 Fax : +82-31-8041-0599 steadily to cope with the corrosion problem by applying plasma on Si-wafer supporters such as etch ring, focus ring, shield ring, etc. ${ }^{2,3)}$

It is well known that residual $\mathrm{Si}$ in the RBSC plays an important role on mechanical properties of the body. Its control, however, is not an easy task due to the interrelated complexity involved between pore size and distribution, ability of Si infiltration, formed green density, etc., which depend on mainly particle size of the starting raw materials. ${ }^{4-7)}$ Thus, many studies have focused on the formed microstructure and mechanical properties in terms of raw materials, its particle size, and the amount of added carbon. However, the effects of residual Si in plasma etching have rarely been studied. ${ }^{7-10)}$ Since green body microstructure decides the size and shape of residual $\mathrm{Si}$ in a reactionbonded body, it is believed that it also critically affects etcher part's life and wafer's rejection rate, especially during the etching process of semiconductors.

This study involves in the effects of mixing ratio of starting raw materials on microstructure development of residual Si in RBSC, and the corresponding RIE (reactive ion etching) behavior. We prepared RBSC samples with various mixing ratios by using four different sizes of SiC particles. Then, we evaluated the microstructure of the sintered bodies and their etching behavior. 


\section{Experimental Procedure}

Starting raw materials include $95 \mu \mathrm{m}, 33 \mu \mathrm{m}, 7 \mu \mathrm{m}$, and $2.6 \mu \mathrm{m}$ of $\mathrm{SiC}$ particles (>99.3\%, Showa Denko, Japan), Phenol resin (Phenol, KC-4100B, Kangnam Chemical Co. Ltd., Korea) as a binder and Si (Chunks, 99.99999\%, Prime Grade, MEMC) as the infiltrating material. Table 1 shows the prepared batch compositions of various mixing ratios, which will be tested to identify the optimum microstructure with the minimal size of residual Si region.

Figure 1 shows the flow of sample manufacturing and etching test for reaction-bonded body of SiC. First, $45 \mathrm{wt} \%$ of methyl alcohol and $5 \mathrm{wt} \%$ of phenol resin (based on dry weight of $\mathrm{SiC}$ particles) were mixed with $\mathrm{SiC}$ batch of predetermined mixing ratio in a mixer for $15 \mathrm{~min}$. The mixed slurry were spray dried into granules (inlet temperature of $90^{\circ} \mathrm{C}$, outlet temperature of $60^{\circ} \mathrm{C}$, feed rpm of 16 , disk rpm of 900). The prepared granules were cold-isostatically-pressed (Dr. CIP, Kobelco, Japan) for $5 \mathrm{~min}$ at $130 \mathrm{MPa}$ into green body of $ø 100 \times 300 \mathrm{~mm}$.

Table 1. Prepared SiC Samples with Different Mixing Ratios of SiC Particles

\begin{tabular}{cccccc}
\hline \multirow{2}{*}{ Sample No. } & \multicolumn{5}{c}{ Mixing ratio of SiC particles (wt\%) } \\
\cline { 2 - 6 } & $95 \mu \mathrm{m}$ & $33 \mu \mathrm{m}$ & $7 \mu \mathrm{m}$ & $2.6 \mu \mathrm{m}$ & Total \\
\hline DS 1 & 60 & 20 & 10 & 10 & 100 \\
DS 2 & 50 & 15 & 15 & 20 & 100 \\
DS 3 & 40 & 15 & 20 & 25 & 100 \\
DS 4 & 30 & 10 & 30 & 30 & 100 \\
DS 5 & 20 & 10 & 20 & 50 & 100 \\
DS 6 & 20 & 10 & 10 & 60 & 100 \\
\hline
\end{tabular}

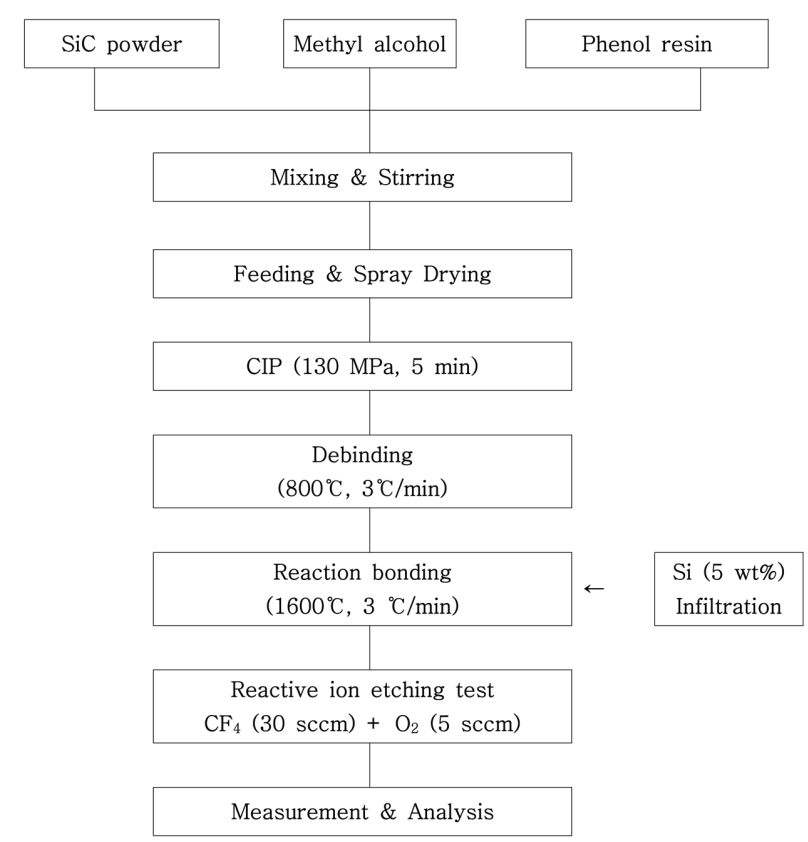

Fig. 1. Flow of experimental process.
Thermosetting phenol resin was carbonized in a dewaxing furnace by heating at a rate of $3^{\circ} \mathrm{C} / \mathrm{min}$ and holding at $800^{\circ} \mathrm{C}$ for $5 \mathrm{~h}$, which resulted in green body with many pores for easy Si infiltration. Dewaxed green bodies were stacked on a graphite felt in a vacuum furnace under a reduced pressure of $300 \mathrm{Torr}$, and heated at a rate of $3^{\circ} \mathrm{C} / \mathrm{min}$ and held at $1,600^{\circ} \mathrm{C}$ in $\mathrm{Ar}$ atmosphere for $1 \mathrm{~h}$ for Si infiltration and subsequent reaction bonding. The reaction-sintered samples were machined into $10 \times 10 \times 1 \mathrm{~mm}$, and mirror polished for microstructure observation under an optical microscope (Axio observer A1m, ZEISS, Germany) and an SEM (SUPRA55, ZEISS, Germany). The sintered apparent density was measured according to ASTM C20.

RIE test (SHE-4T-250R, Samhan Vac., Korea) was carried out under a dielectric etch condition with a flow of $\mathrm{CF}_{4}$ $(30 \mathrm{sccm})+\mathrm{O}_{2}(5 \mathrm{sccm})$ at $50 \mathrm{~m}$ Torr with power of $300 \mathrm{~W}$ and $13.56 \mathrm{MHz}$. Note that this test condition corresponds to more than $60 \%$ of total etching processes. Each sample was etched for $50 \mathrm{~h}$ and its weight reduction was measured with a precision balance (XB Series, CAS, Korea) and compared with each other. Etching behavior in terms of residual $\mathrm{Si}$ was also observed by analyzing the surface microstructure of each sample by CLSM (VK-X130K, Keyence, Japan) and SEM.

\section{Results and Discussion}

\subsection{Microstructure and density of reaction-bonded body}

Figure 2 shows images of optical microscopy on the prepared RBSC samples. It clearly indicates that gaps between coarse particles are filled with fine $\mathrm{SiC}$ grains forming a dense microstructure when the added amount of $2.6 \mu \mathrm{m}$-particle is increased from 10 to $50 \mathrm{wt} \%$, while that of $9.5 \mu \mathrm{m}$ particle is decreased from 60 down to $20 \mathrm{wt} \%$. When the added amount of $2.6 \mu \mathrm{m}$-particle is $50 \mathrm{wt} \%$, the residual $\mathrm{Si}$ region is fine and uniform as shown in Fig. 2(e).

When the addition of $2.6 \mu \mathrm{m}$-particle has increased to $60 \mathrm{wt} \%$, however, the residual Si region becomes more fine, but part of it becomes irregular shaped with sizes of $20 \sim 80 \mu \mathrm{m}$ as shown in Fig. 2(f). This observation contradicts the result by Park et al., ${ }^{11)}$ which reported pore sizes are normally in the range of $1 / 10 \sim 1 / 20$ of the raw material size. This observation, however, is in agreement with the report by Shin et al., ${ }^{12)}$ which showed a similar gap shapes when gaps were densely packed. We then conclude that the most fine and uniform microstructure can be produced when $50 \mathrm{wt} \%$ of $2.6 \mu \mathrm{m}$-particles fill gaps between coarse particles.

Figure 3 shows the density of each sample. In agreement with the above results of denser microstructure by increased fine particles, samples of Fig. 3(e) and (f) have an average density above $3.0 \mathrm{~g} / \mathrm{cm}^{3}$. Samples of Fig. 3(a) and (b) with coarse microstructure, on the contrary, have an average density below $2.9 \mathrm{~g} / \mathrm{cm}^{3}$. Although Fig. 2(f) seems to be more dense compared to Fig. 2(e), its density as shown in 


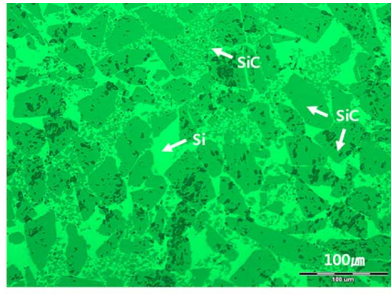

(a)

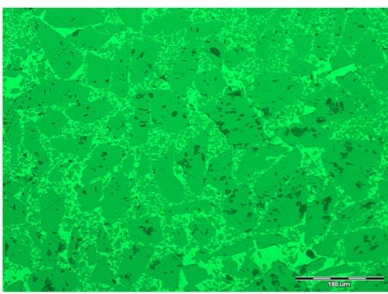

(c)

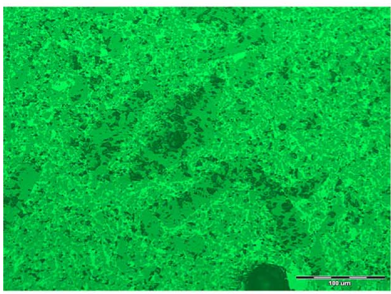

(e)

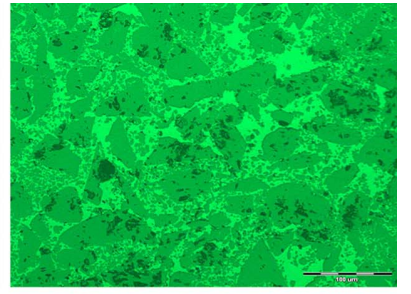

(b)

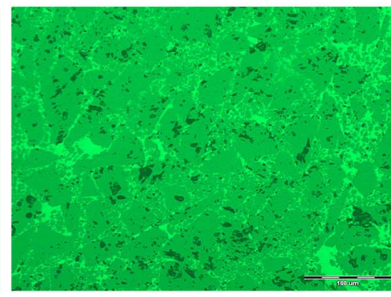

(d)

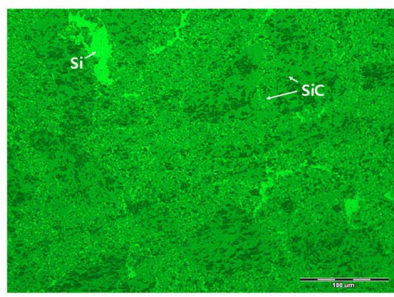

(f)
Fig. 2. Optical microscope images of RBSC specimens fabricated using different ratios of $\mathrm{SiC}$ powders $(\times 200)$ : (a) DS1, (b) DS2, (c) DS3, (d) DS4, (e)DS5, (f) DS6.

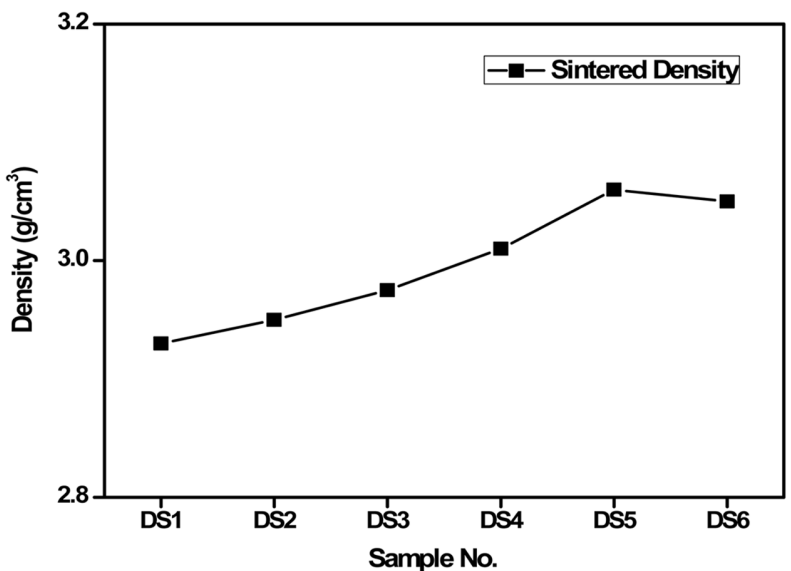

Fig. 3. Variation of sintered density of RBSC specimens with different mixing ratios of $\mathrm{SiC}$ particles.

Fig. 3 is slightly lower due to the nonuniform gap formation and irregular residual Si region. We conclude that denser microstructure can increase body density of RBSC only when the residual Si region is uniformly developed.

\subsection{Change of surface roughness by $\mathrm{CF} / \mathrm{O}_{2}$ etching}

Figure 4 shows 3D surface images of RBSC samples after etching, and Table 2 summarizes the surface roughness changes before and after etching. Surface roughnesses (Ra.) of $0.35 \sim 0.45 \mu \mathrm{m}$ before etching increase to $19.75 \sim 22.28 \mu \mathrm{m}$ after etching. Even after due consideration of error in mea-

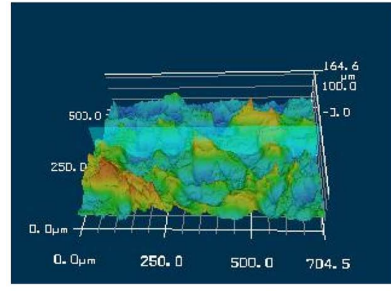

(a)

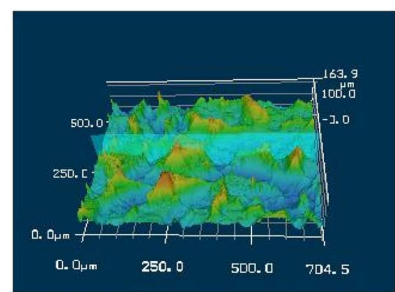

(c)

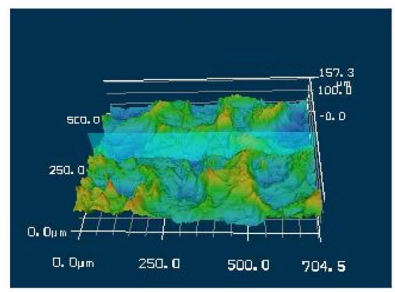

(e)

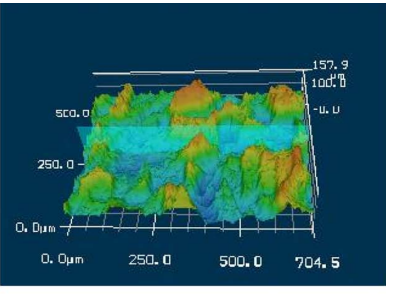

(b)

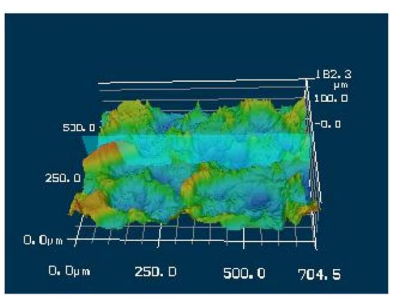

(d)

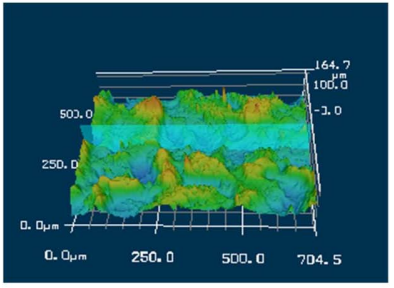

Fig. 4. 3D micro-morphology of RBSC specimens with different mixing ratios of $\mathrm{SiC}$ particles: (a) DS1, (b) DS2, (c) DS3, (d) DS4, (e)DS5, (f) DS6.

Table 2. Surface Roughness (Ra) of RBSC Fabricated Using Different Ratios of SiC Powders

\begin{tabular}{ccc}
\hline Sample No. & Before Etch $(\mu \mathrm{m})$ & After Etch $(\mu \mathrm{m})$ \\
\hline DS 1 & 0.43 & 22.28 \\
DS 2 & 0.45 & 21.54 \\
DS 3 & 0.38 & 20.15 \\
DS 4 & 0.40 & 19.89 \\
DS 5 & 0.35 & 19.75 \\
DS 6 & 0.37 & 19.77 \\
\hline
\end{tabular}

suring surface roughness of differently-developed microstructure, the general trend is rather consistent.

The coarse-structured DS1 sample shows the highest Ra. number, as indicated as largely distributed red-colored parts in Fig. 4(a), that represent large surface unevenness. In the cases of DS2 DS6 samples, where $98 \mu \mathrm{m}$-coarse particles decrease and $2.6 \mu \mathrm{m}$-fine particles increase, surface roughness becomes gradually even in agreement with the trend of optical images in Fig. 2. This result implies that the fine particle addition is important to decrease residual $\mathrm{Si}$ region and to have a better surface morphology after etching in the RBSC body. Fig. 5 is weight loss data by etching for each sample, which indicates that a change of surface morphology eventually affected the etched amount.

Sample weights are in the range of $0.58 \sim 0.61 \mathrm{~g}$ before etching, probably due to the density difference by different mixing ratios of raw materials. After etching, however, we 


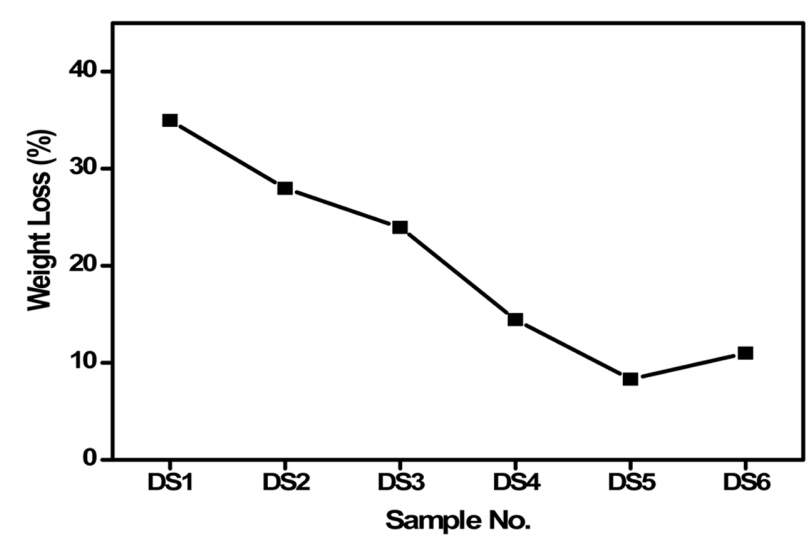

Fig. 5. Weight-loss curve of RBSC specimens after etching in $\mathrm{CF}_{4} / \mathrm{O}_{2}$ plasma at a bias power of $300 \mathrm{~W}$ with different mixing ratios of $\mathrm{SiC}$ particles.

confirm that DS1 DS3 samples show relatively higher weight losses, while DS4 $\sim$ DS6 samples sintered to have a fine microstructure show relatively lower weight loss. Especially, the DS5 sample has the lowest weight decrease by etching.

Figure 6 is SEM images of two extreme samples, DS1 and DS5, after initial etching for one hour, which resulted in the largest weight decrease. In both DS1 and DS5 cases, we confirm that etching takes place firstly in the residual $\mathrm{Si}$ region. We believe that the etching mechanism involves two steps: The gases added, $\mathrm{CF}_{4}$ and $\mathrm{O}_{2}$, react and activate each other, forming $\mathrm{COF}_{2}, \mathrm{CO}$, and $\mathrm{CO}_{2}$ gases and $\mathrm{F}$ and $\mathrm{F}_{2}$ radicals. Subsequently, free fluorine first attacks $\mathrm{Si}$ on sample surface to form $\mathrm{SiF}_{\mathrm{x}}$ for etching. It is known that $\mathrm{Si}$ has $3 \sim 4$ times higher etching rate compared to $\mathrm{SiC}$ at room temperature. $^{13-15)}$

Figure 7 is microstructure of samples after $50 \mathrm{~h}$ etching. We confirm that the DS1 sample forms deep pits by preferential etching on the residual Si region, and coarse- and intermediate-sized $\mathrm{SiC}$ particles remain like islands. We observe a similar situation on the DS5 sample, but pits on the residual Si region are just under-cut shapes.

Figure 7(a) shows the formation of coarse craters on the $\mathrm{SiC}$ surface, which is a typical phenomenon by corrosive ion bombardment. It implies that $\mathrm{SiC}$ corrodes rather physically by plasma-accelerated ions instead of by chemical corrosion considering the activation energy difference. Especially, the DS1 sample has much coarser craters compared to those of the DS5 sample due to more concentrated electric field on the island-shaped $\mathrm{SiC}$ as residual $\mathrm{Si}$ is progressively etched away by forming pits. We assume, therefore, field-activated ion bombardment along could accelerates physical corrosion and forms much coarser craters.

Thus the increase in etching time for DS1 DS3 samples of more residual Si region could lead to increase in field nonuniformity and results in higher etching amount. With the mixing ratios of DS4 DS6 samples, it seems that low surface roughnesses (Ra.) are resulted from the evenly-developed microstructure during etching. We deduced that their

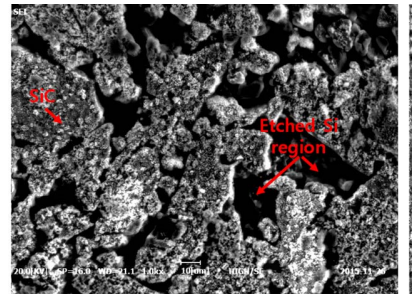

(a)

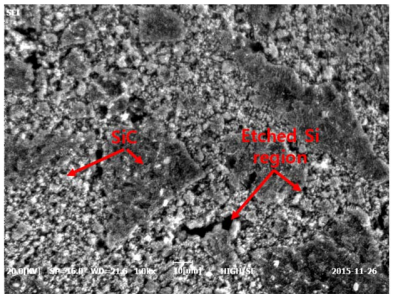

(b)
Fig. 6. SEM images of RBSC specimens after $1 \mathrm{~h}$ in $\mathrm{CF}_{4} / \mathrm{O}_{2}$ etching: (a) DS1, (b) DS5.

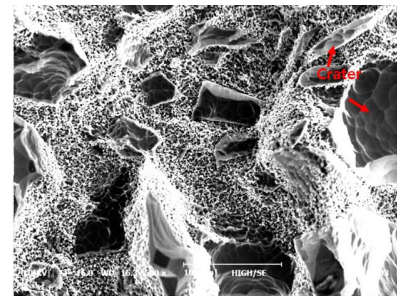

(a)

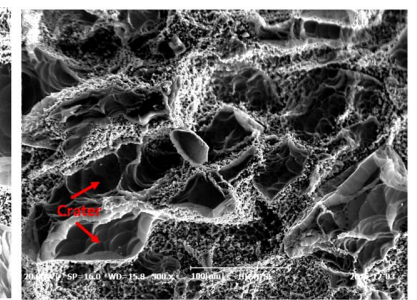

(b)
Fig. 7. SEM images of RBSC specimens after $50 \mathrm{~h}$ in $\mathrm{CF}_{4} /$ $\mathrm{O}_{2}$ etching: (a) DS1, (b) DS5.

finely-developed residual Si region generate finer pits in the corroded Si region, and their exposure to the relatively-uniform field distribution reduces the amount of etching.

\section{Conclusions}

In this study, we prepared RBSC samples with various mixing ratios by using four different sizes of $\mathrm{SiC}$ particles. We evaluated microstructures of the sintered bodies and their etching behavior in terms of mixing ratio of $\mathrm{SiC}$ particles, and conclude:

1. When the added amount of $2.6 \mu \mathrm{m}-\mathrm{SiC}$ was $50 \mathrm{wt} \%$, the sample showed the highest sintered density, and the residual Si region produced fine microstructure. When it had increased to $60 \mathrm{wt} \%$, however, the sample became slightly less dense, and the residual Si region became partly nonuniform.

2. After etching by $\mathrm{CF}_{4} / \mathrm{O}_{2}$ for $50 \mathrm{~h}$, surface roughness (Ra.) of all sintered samples increased, and their weights decreased. The variations were relatively high for the DS1 DS3 samples with the coarse-microstructure of Si region, while they were relatively low for the DS4 DS6 samples with the fine-microstructure of Si region.

3. During etching process, the residual Si region was rapidly removed and formed pits isolating $\mathrm{SiC}$ particles as islands. This led to more intensified ion field on the $\mathrm{SiC}$ islands, and caused physical corrosion on them. Increased addition of $2.6 \mu \mathrm{m}-\mathrm{SiC}$ particles produced finer residual $\mathrm{Si}$ region, these changes were attributed to decrease at etched surface roughness (Ra.), as well as the weight loss decrease after etching process by following the above etching mechanism. 


\section{REFERENCES}

1. T. H. Han, "Next-Generation Semiconductor Process/Device Development Trends (in Korean)," pp. 50-54, KEIT, PD Issue Report Vol. 11-04, Seoul, 2009.

2. J. Y. Ryu, "Silicon Carbide Components for a Semiconductor Manufacturing Process/Materials Technical Analysis Reports (in Korean)," pp. 3-12, KISTI, IOD Report (Serial \#:4-0001) Seoul, 2005.

3. S. K. Jun, "Structural Ceramics Industry Competitiveness Survey (in Korean)," pp. 35-42, 188-190, Korea Fine Ceramic Association, Korean Trade Commission, Seoul, 2010.

4. J. N. Ness and T. F. Page, "Micro-structural Characterization of Reaction-Bonded Silicon Carbide," J. Mater. Sci., 21 1377-97 (1986).

5. P. Popper, "The Preparation of Dense Self-Bonded Silicon Carbide,” pp. 209-219, in Special Ceramics, Proper, P., Ed., Academic Press. New York, 1960.

6. R. Pampuch, E. Warasek, and J. Bialoskorski, "Reaction Mechanism in Carbon-Liquid Silicon Systems at Elevated Temperature." Ceram. Int., 12 99-106 (1986).

7. R. L. Mehan, "Effect of SiC Content and Orientation on the Properties of Si/SiC Ceramic Composite," J. Mater. Sci., 13 358-66 (1978).

8. C. B. Lim and T. Iseki, "Transport of Fine-Grained $\beta$-SiC in
SiC/Liquid Si System,” Adv. Ceram. Mater., 3, 291-293 (1988).

9. C. B. Lim and T. Iseki, "Strength of Reaction Sintered SiC Heterogeneously Containing Fine-Grained $\beta$-SiC," $J$. Mater. Sci., 23 3248-53 (1988).

10. C. W Forrest, P. Kennedy, and J. V. Shennan, "The Fabrication and Properties of Self-Bonded Silicon Carbide Bodies,” pp. 99-127, Special Ceramics Vol. 5, British Ceram., Res. Asso. U.K., 1972.

11. H. C. Park, "Effect of Green Microstructure on Sintered Microstructure and Mechanical Properties of ReactionBonded Silicon Carbide (in Korean)," J. Korean Ceram. Soc., 36 [1] 97-105 (1999).

12. H. I. Shin, "Silicon Melt Infiltration of Reaction-Bonded Silicon Carbide (in Korean)," J. Korean Ceram. Soc., 39 [7] 693-98 (2002).

13. J. Sugiura, W. J. Lu, K. C Cadien, and A. J. Steckl, "Reactive Ion Etching of $\mathrm{SiC}$ Thin Films Using Fluorinated Gases," J. Vac. Sci. Technol. B, 4 [1] 349-54 (1986).

14. G. S. Oehrlein, P. J. Matsuo, and M. F. Doemling, "Study of Plasma-Surface Interactions : Chemical Dry Etching and High-Density Plasma Etching," Plasma Sources Sci. Technol., 5 193-99 (1996).

15. J. Hong, R. J. Shul, L. Zhang, and L. F. Lester, "Plasma Chemistries for High Density Plasma Etching of SiC," J. Elect. Mater., 28 [3] 196-201 (1999). 